\title{
ОПРЕДЕЛЕНИЕ КОЛИЧЕСТВЕННОГО СОДЕРЖАНИЯ ДЕИТЕРИЯ В МЕЧЕНЫХ ОРГАНИЧЕСКИХ СОЕДИНЕНИЯХ С ПОМОЩЬЮ ПОЛЕВОЙ МАСС-СПЕКТРОМЕТРИИ
}

M. LIITMAA, Silvia RANG, O. EISEN. MARGITUD ORGAANILISTES OHENDITES SISALDUVA DEUTEERIUMI HULGALINE MÄARAMINE VALLJAIONISATSIOONI-MASSISPEKTROMEETRIA ABIL

M. LIITMAA, Silvia RANG, O. EISEN. QUANTITATIVE DETERMINATION OF DEUTERIUM IN LABELLED ORGANIC COMPOUNDS BY FIELD IONIZATION MASS SPECTROMETRY

В настоящее время определение изотопного состава меченых органических соединений проводят обычно с помощью электронно-ударной масс-спектрометрии по пикам молекулярных ионов в масс-спектре объекта исследования. Однако в результате электронной бомбардировки молекулы многих соединений либо полностью разрушаются, либо дают в масс-спектрах интенсивные пики ионов $(M-1)^{+},(M-2)^{+}$, что делает практически невозможной количественную интерпретацию экспериментальных данных ['].

Известно, что при полевой ионизации и диссоциации молекул происходит преимущественно простой разрыв химических связей [ $\left.{ }^{2}\right]$, роль перегруппировочных процессов незначительна, а пики молекулярных ионов обладают высокой интенсивностью [3]. Поэтому нами для количественного определения дейтерия в некоторых меченых соединениях был выбран метод полевой масс-спектрометрии. Для проверки достоверности полученных этим методом данных были сняты и электронно-ударные масс-спектры при различных энергіях ионизирующих электронов. Результаты сравнительного исследования обогащенных дейтерием толуола, бензола и различных проб фенилацетилена приведены в таблице. Стандартная ошибка $\left[{ }^{4}\right]$ при электронно-ударном определении не превышала 0,1 , а при полевой ионизации $-0,6 \%$.

Расхождения между данными, полученными при различных энергиях электронов незначительны, несмотря на то что в масс-спектрах некоторых проб фенилацетилена имелись сравнительно интенсивные пики высших примесей. Процент дейтерирования, определенный по полевым спектрам, как правило, был несколько ниже. Это можно объяснить, вероятно, тем, что на эмиттере ионов происходит интенсивный водороддейтериевый обмен между адсорбированными молекулами воды и изучаемого соединения. В этом можно было убедиться и в ходе эксперимента: соотношение интенсивностей пиков ионов с $m / e 18 / 19$ (т. е. $\left.\mathrm{H}_{2} \mathrm{O}^{+} \cdot / \mathrm{H}_{3} \mathrm{O}^{+}\right)$в фоновом спектре до измерения было больше, чем после работы с меченым препаратом. 
Содержание дейтерированной формы в исследованных образцах

\begin{tabular}{|c|c|c|c|}
\hline \multirow{3}{*}{ Образец } & \multicolumn{3}{|c|}{$\begin{array}{c}\text { Содержание дейтерированно } \\
\text { формы, \% }\end{array}$} \\
\hline & \multicolumn{2}{|c|}{ Электронный удар } & \multirow{2}{*}{$\begin{array}{r}\text { Полевая } \\
\text { нонизаци }\end{array}$} \\
\hline & 50 эв & 18 эв & \\
\hline $\left.\begin{array}{l}\mathrm{C}_{6} \mathrm{H}_{5}-\mathrm{CH}_{2} \mathrm{D} \\
\mathrm{C}_{6} \mathrm{H}_{5}-\mathrm{CH}_{3}\end{array}\right\}$ & & $96,2^{*}$ & 96,0 \\
\hline $\left.\begin{array}{l}\mathrm{C}_{6} \mathrm{H}_{5} \mathrm{D} \\
\mathrm{C}_{6} \mathrm{H}_{6}\end{array}\right\}$ & & $92,7^{* *}$ & 92,4 \\
\hline $\left.\begin{array}{l}\mathrm{C}_{6} \mathrm{H}_{5}-\mathrm{C} \equiv \mathrm{CD} \\
\mathrm{C}_{6} \mathrm{H}_{5}-\mathrm{C} \equiv \mathrm{CH}\end{array}\right\}$ & 25,9 & 25,8 & 25,2 \\
\hline 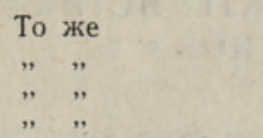 & $\begin{array}{r}19,3 \\
5,6 \\
13,1 \\
10,0\end{array}$ & 10,1 & $\begin{array}{r}18,1 \\
5,7 \\
12,9 \\
9,4\end{array}$ \\
\hline
\end{tabular}

* Концентрация дейтерия по паспорту 96,3\%. Опыт проводился при энергии электронов 8 эв.

** Концентрация дейтерия по паспорту 92,7\%. Опыт проводился при энергии электронов 10 эв.

Для уменьшения влияния изотопного обмена как при электронном ударе, так и при полевой ионизации проводилось многократное промывание масс-спектрометра исследуемым соединением (3-5 раз по $\sim 5$ мин).

Полученные данные свидетельствуют о том, что метод полевой массспектрометрии может быть успешно применен для определения изотопного состава меченых дейтер.ием соединений. Необходимо только учитывать, что из-за интенсивного изотопного обмена на эмиттере ионов результаты могут быть несколько занижены (завышены).

Опыты проводились на масс-спектрометре MX-1303. Конструкция полевого источника описана в [5]; разность потенциалов между эмиттером и катодом составляла $3 \kappa B$ (среднее поле). Температура системы напуска, камеры анализатора и источника ионов составляла $200^{\circ} \mathrm{C}$.

\section{Л И ТЕ Р А Т У А}

1. B i emann, K., Mass Spectrometry. Organic Chemical Applications. Mc Graw Hill Book Company, INC. New York, 1962 ; H i 1 l, H. C., Introduction to Mass Spectrometry. Sec. Edition, Heyden \& Son. Ltd. London, 1972.

2. Гольденфельд И. В., Коростышевский И. 3., Ж. физ. химии, 43, 2596 (1969).

3. Алексанкин М. М., Самченко И. П., Коростышевский И. З., Филе леева Л. И., Ди брова П. С., Н азаренко В. А., Мисчанчук Б. Г., Каталог полевых масс-спектров органических соединений, Киев, 1976.

4. Горд н А., Форд Р., Спутник химика, М., 1976 , с. 515 .

5. Л ийтм а а М. М., I Республиканская конференция молодых ученых-химиков. $20-22$ мая 1975 г., Тезисы докладов, Таллин, 1975, с. 93. 